$\underline{\text { Avicenna Journal of Nursing and Midwifery Care - ISSN 2676-5748 }}$

\title{
Psychometric Properties of the Persian Version of the Exercise Self-Efficacy Scale in Pregnant Women
}

\author{
Maryam Alborzi ${ }^{1}$, Seyedeh Zahra Masoumi2 ${ }^{*}$, Farzaneh Soltani ${ }^{2}$, Farideh Kazemi ${ }^{3}$, Lily Tapak $^{4}$
}

1. MSc Student, Department of Midwifery and Reproductive Health, School of Nursing and Midwifery, Hamadan University of Medical Sciences, Hamadan, Iran

2. Associate Professor, Mother and Child Care Research Center, School of Nursing and Midwifery, Hamadan University of Medical Sciences, Hamadan, Iran

3. Assisstant Professor, Mother and Child Care Research Center, School of Nursingand Midwifery, Hamadan University of Medical Sciences, Hamadan, Iran

4. Assistant Professor, Department of Statistics, School of Public Health, Hamadan University of Medical Sciences, Hamadan, Iran

Article Info $\quad$ ABSTRACT

Received: 2021/04/07;

Accepted: 2021/10/02;

Published Online: 2021/12/21

10.30699/ajnmc.29.4.273

Original Article

Use your device to scan and read the article online

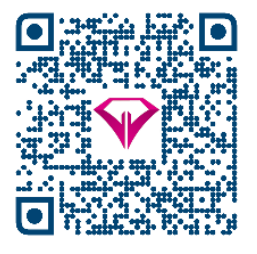

How to Cite This Article:

Alborzi M, Masoumi S Z, Soltani F, Kazemi F, Tapak L. Psychometric Properties of the Persian Version of the Exercise Self-Efficacy Scale in Pregnant Women. Avicenna J Nurs Midwifery Care. 2021; 29(4): 273-283

Introduction: Proper and adequate physical activity during pregnancy significantly impacts maternal health and fetal development. Unfortunately, no tools are available to measure the selfefficacy of sports activity in Iranian pregnant women.

Methods: After translating the questionnaire by the forward-backward method, the quantitative and qualitative face validity and the qualitative and quantitative content validity were assessed. An exploratory factor analysis approach was used to determine the validity of the structure. Simultaneous validity of the instrument was also evaluated using the Scherer General Self-Efficacy Questionnaire. Cronbach's alpha was used to assess the internal stability of the sports self-efficacy questionnaire, and the ICC was used to assess the reproducibility.

Results: Content validity was performed qualitatively and the corrections mentioned by the professors were applied, and none of the options were removed in quantitative content validity. In order to determine the construct validity of the questionnaire, exploratory factor analysis was performed, and the KMO test value was 0.765 . Thus, $37.5 \%$ of the variance was explained by the first factor and $14 \%$ by the second factor. The Scherer general self-efficacy correlation coefficient for pregnant women was 0.446 with P-value $<0.001$. Cronbach's alpha was 0.76 for both domains and 0.81 for the whole scale. ICC was also calculated to be 0.99 for the questionnaire areas and the entire tool.

Conclusion: The Persian version of the questionnaire to assess exercise self-efficacy during pregnancy has good validity and reliability and can measure exercise self-efficacy during pregnancy.

Keywords: Exercise, Psychometrics, Pregnancy, Self-efficacy

Seyedeh Zahra Masoumi, Associate Professor, Mother and Child Care Research Center, Hamadan University of Medical Sciences, School of Nursing and Midwifery, Hamadan, Iran. Email: zahramid2001@gmail.com

Copyright $\odot$ 2021, This is an original open-access article distributed under the terms of the Creative Commons Attribution-noncommercial 4.0 International License which permits copy and redistribution of the material just in noncommercial usages with proper citation. 


\section{روانسنجى نسخة فارسى مقياس خودكار آمدى ورزشى در زنان باردار}

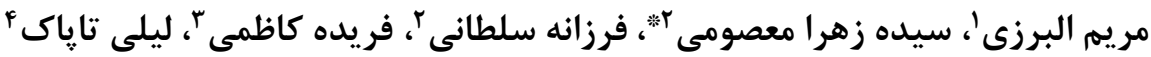

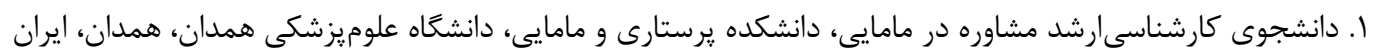

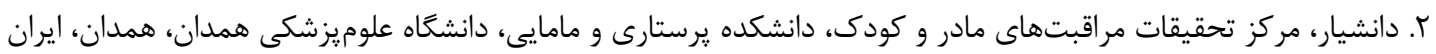

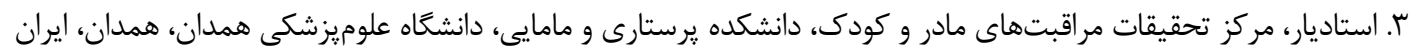

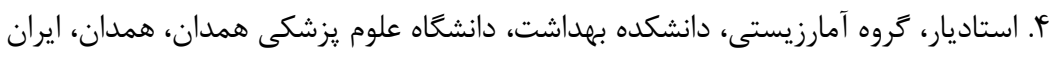

\begin{tabular}{|c|c|}
\hline جكيده & اطلاعات مقاله \\
\hline 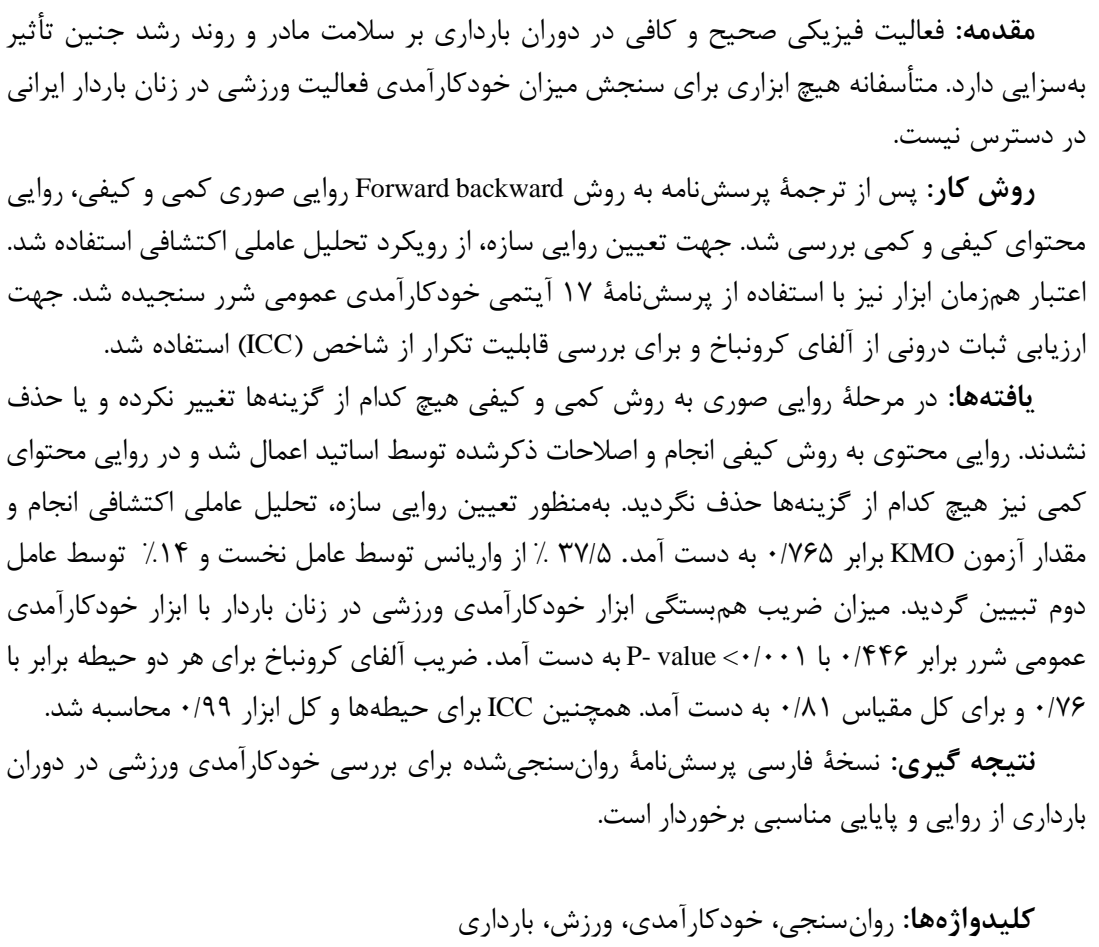 & 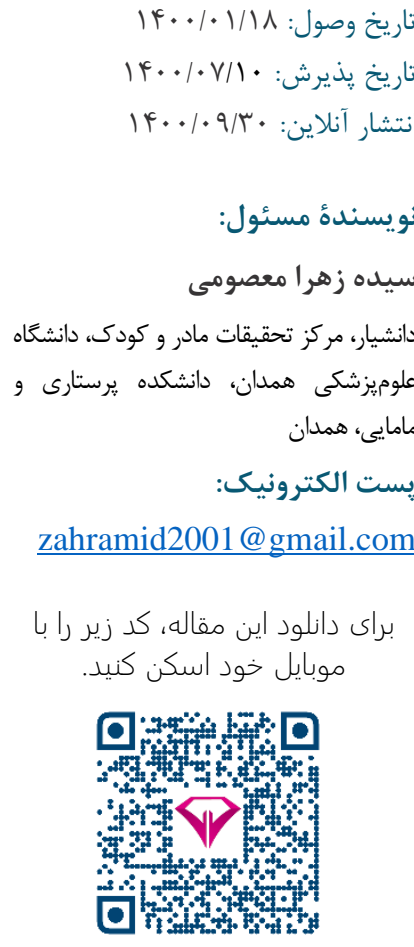 \\
\hline
\end{tabular}

در برابر عوارض پيرى است و اثرات مطلوبى روى خربى خون

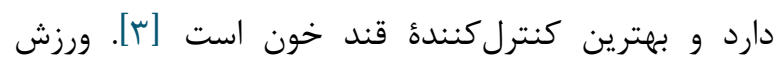

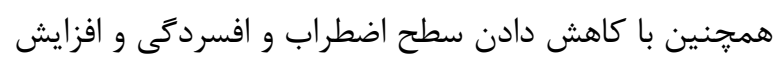

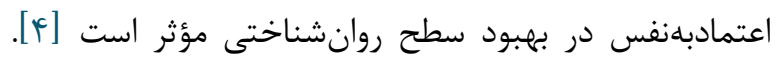

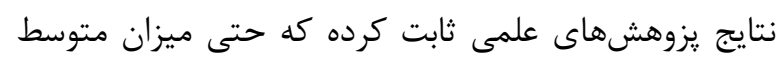

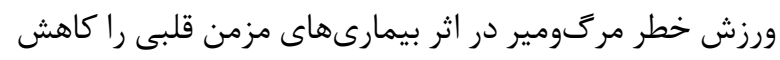

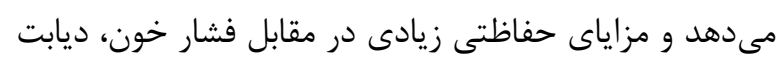

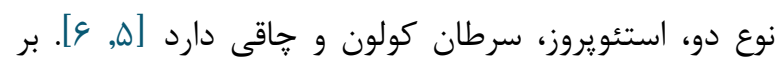

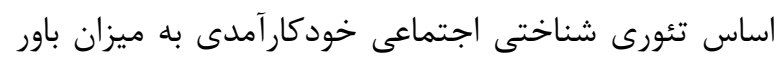

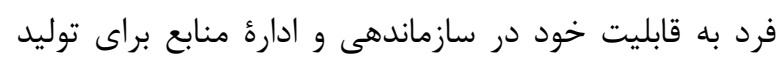

مطالعات متعددى نشان دادهاند كه فعاليت جسمانى

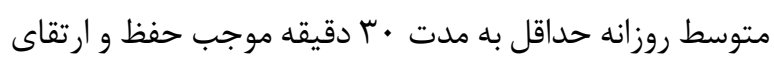

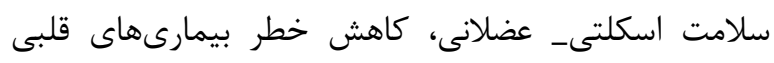

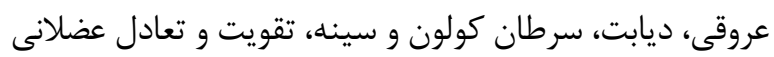

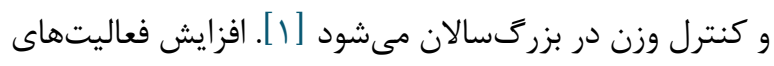

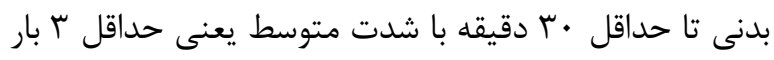

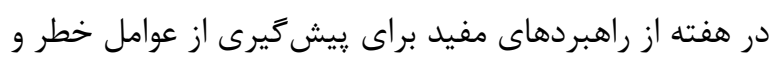

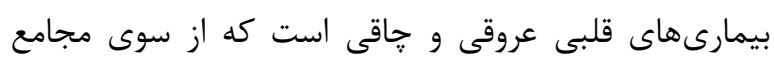

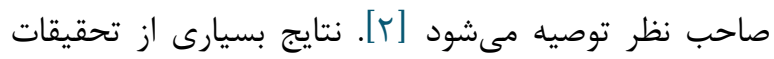

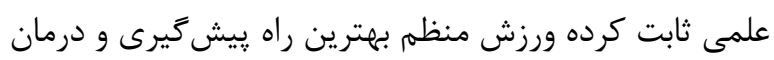




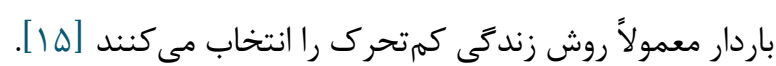

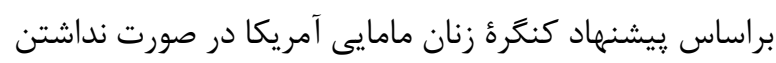

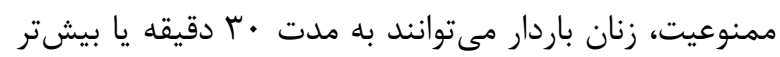

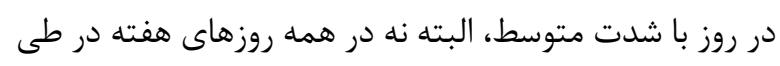
باردارى ورزش كنند. به دليل نبودن مطالعات كافى در سطح

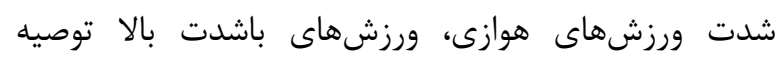

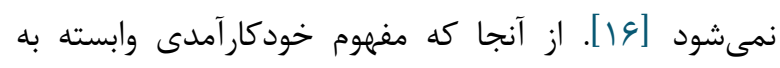

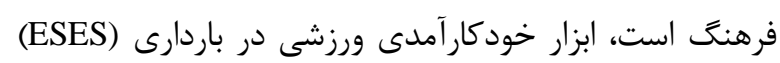

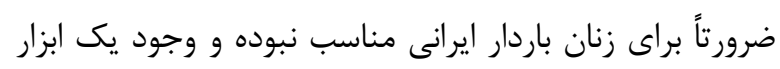

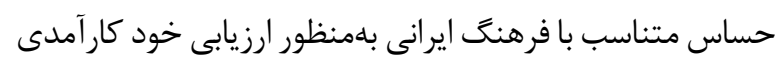

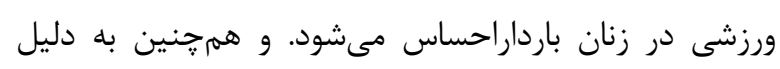

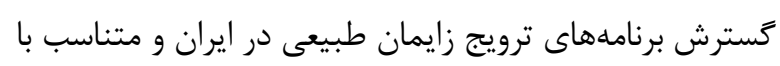

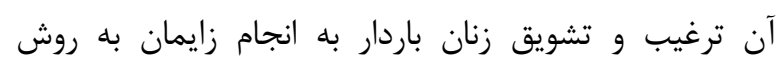

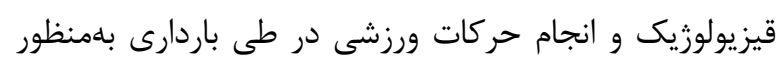

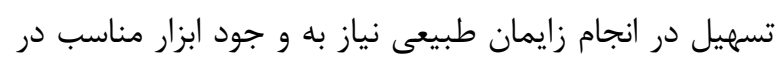

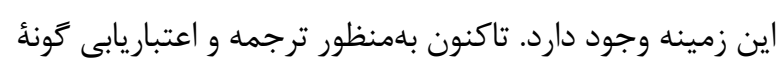

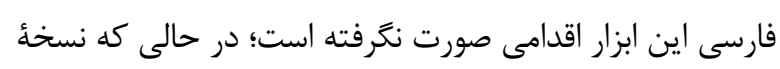

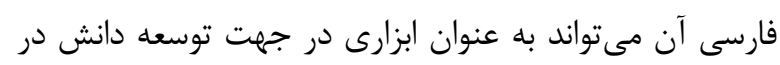

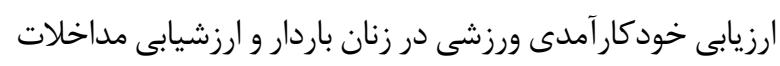

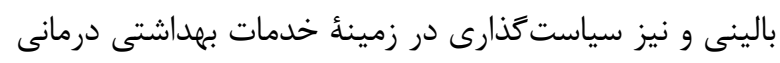

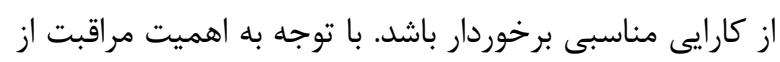

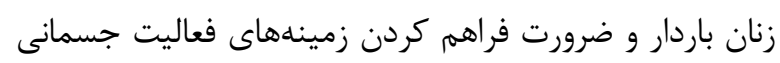

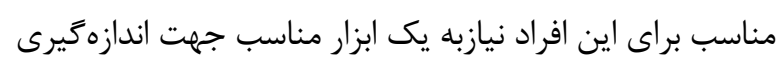

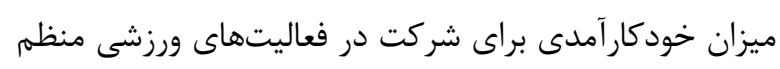

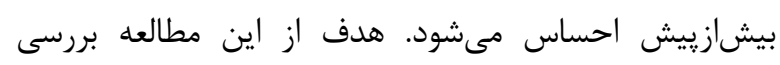

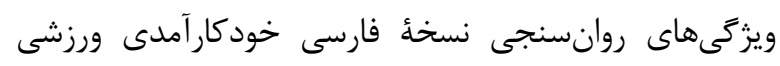
در جمعيت زنان باردار است نسخ

\section{روش كار}

مطالعه حاضر بلممنظور تعيين روانسنجى مقياس

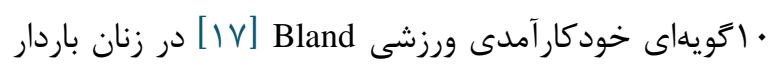

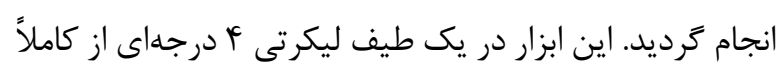

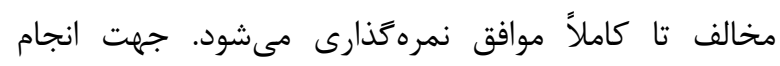
روانسنجى اقدامات زير انجام شد:

\section{ترجمه}

در ابتدا طى مكاتباتى با Bland طراح مقياس خود كار آمدى ورزشى، نسخة اصلى مقياس خودكارآمدى فعاليت ورزشى مقياسي

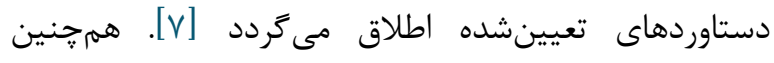
Bandura

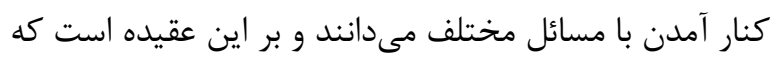

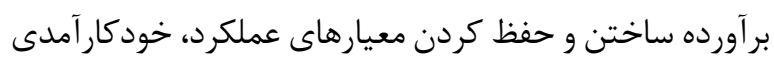

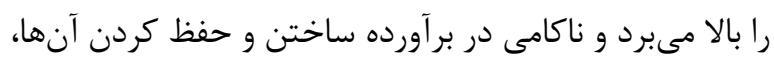

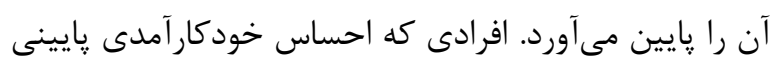

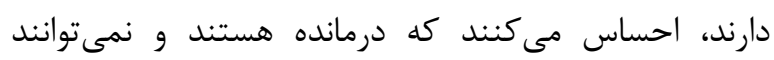

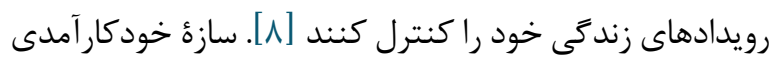

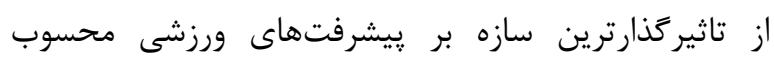

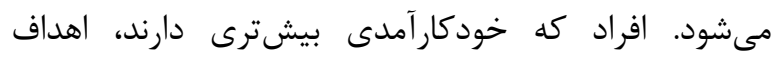

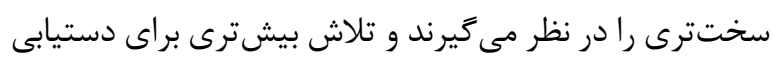

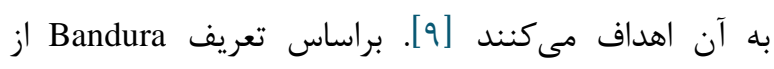

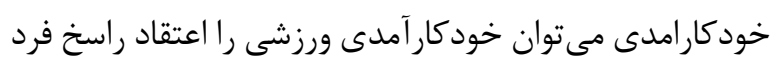
به توانايىهاى خود براى سازماندهى و انجام اعمال موردنياز

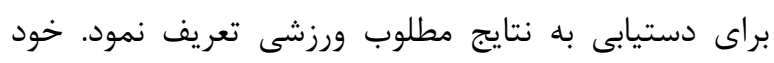

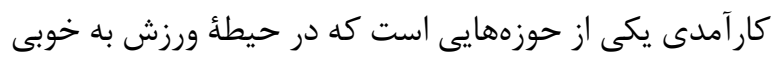

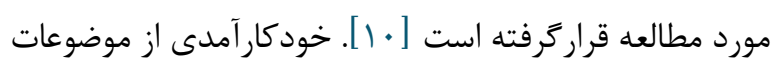

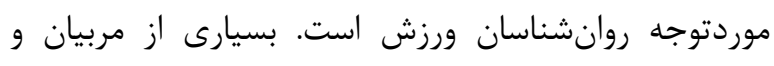
ورزشكاران در سالهاى اخير به اين نتيجه رسيدند كه استفاده

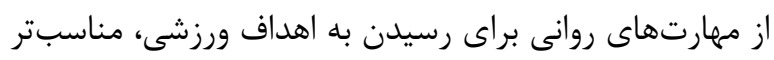

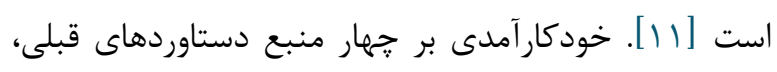

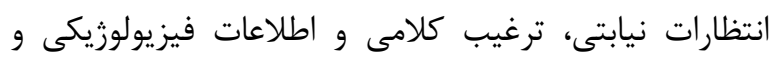

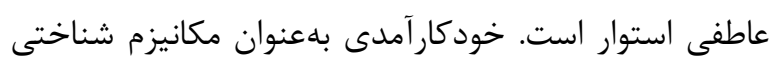

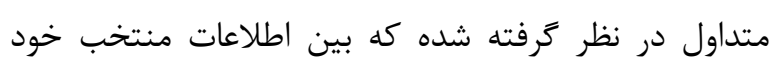

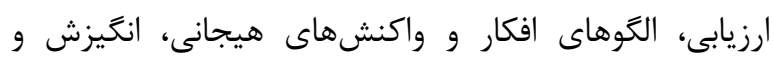

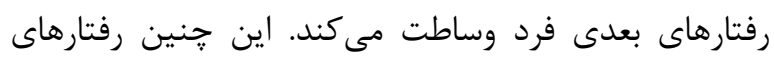

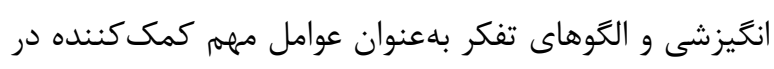

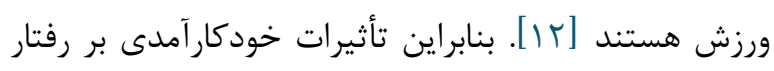
ورزشى در جهار دستهٔ كلى بر رسى مىشود. الف) انتخاب اعمال

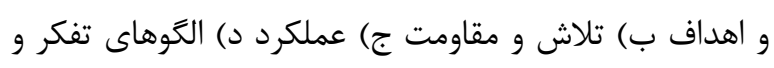

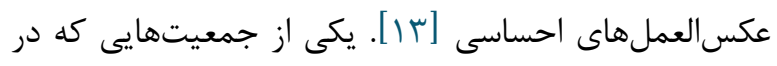

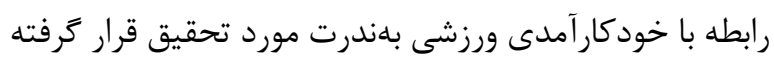

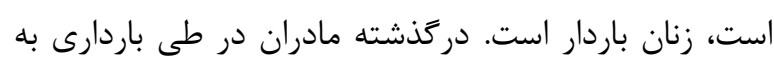

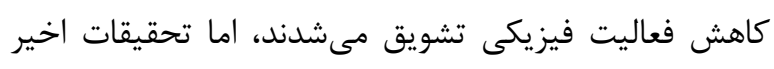

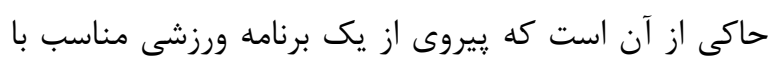

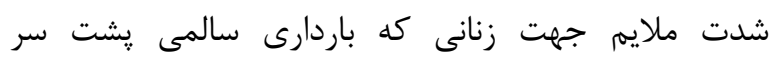

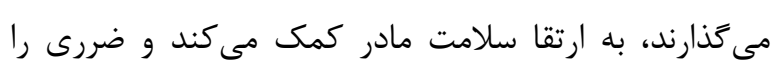
متوجه جنين در حال رشد نمى كند [ع أl]. اما متأسفانه زنان 
PS P آيتم محاسبه شد. در صورتى كه نمره بهدست آمده

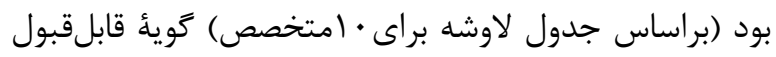

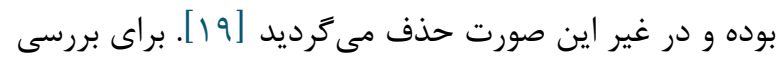
CVI شد و از آنها خواسته شد، با استفاده از ليكرت أن تايى ارتباط

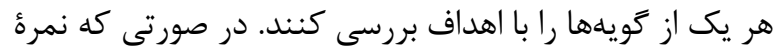

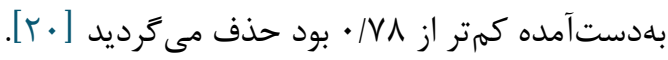

\section{روايى سازه}

تحليل عاملى اكتشافى براى خلاصهسازى دادهها استفاده

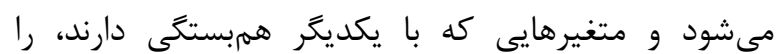

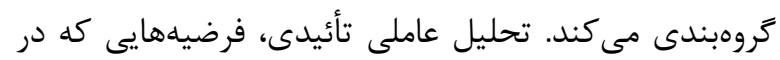

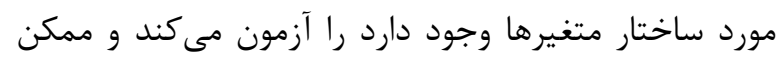

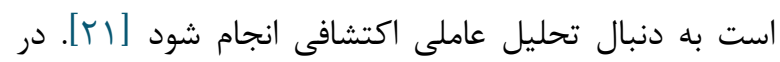

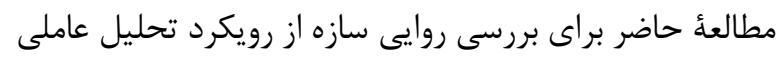

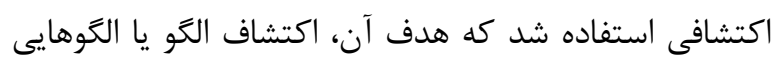

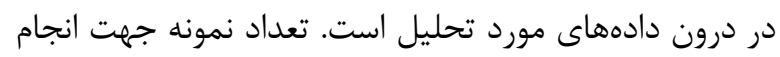

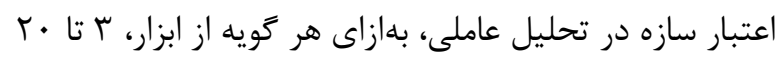

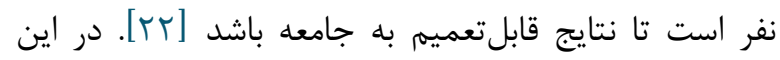

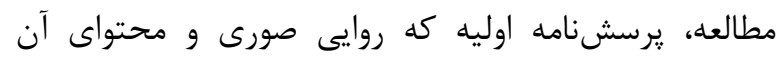

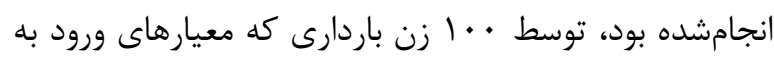

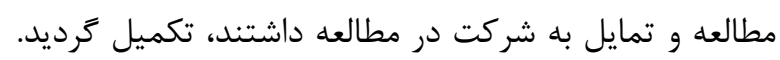

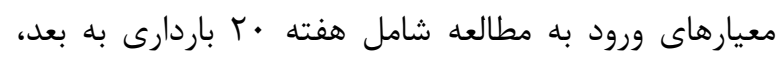
تابعيت ايرانى، داشتن حداقل سواد خواندن و نوشتن، نداشتن

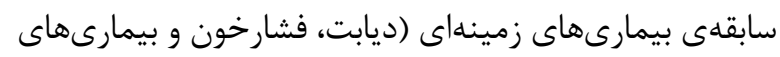

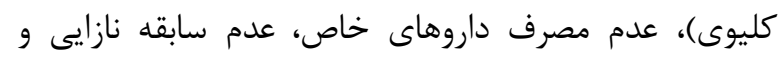

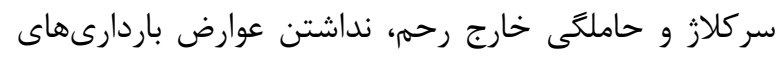

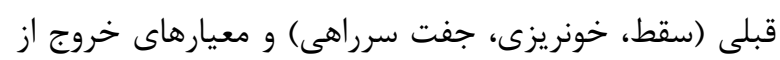

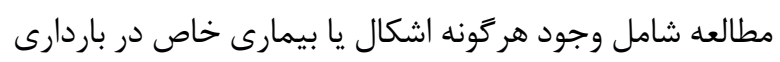

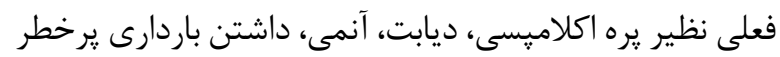

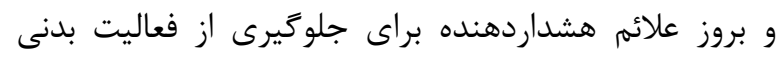

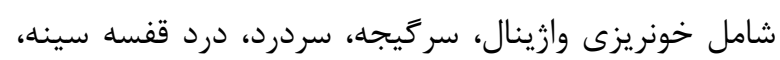

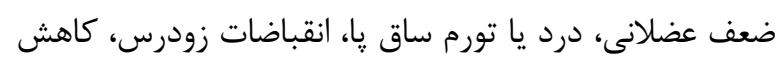

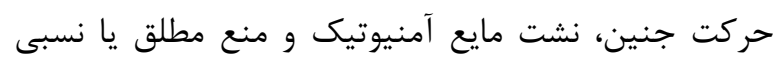
انجام ورزش در باردارى بود. دادهها پِ از جمعآورى وارد نرمافزار (SPSS Inc., Chicago, Ill., USA)

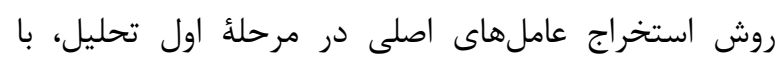

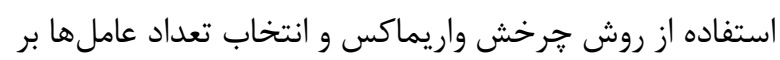

تهيه كرديد. سيس دو تن از افراد مسلط به زبان انخليسى

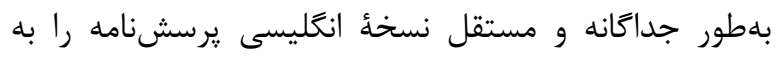
فارسى تر جمه كردند و تمام معادل هاى فارسى در مورد كلمات

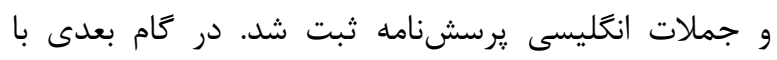
تشكيل Expert panel، دو ترجمأ فارسى يرسشنامهاته و

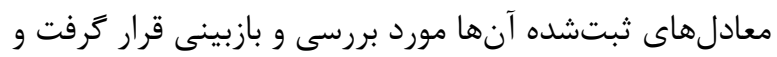

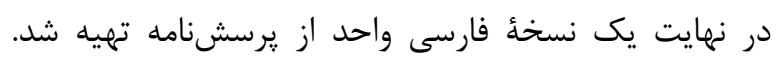

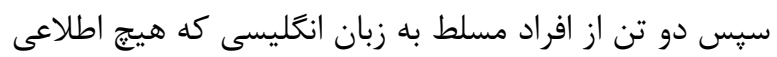

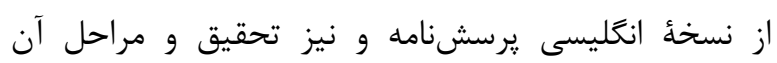

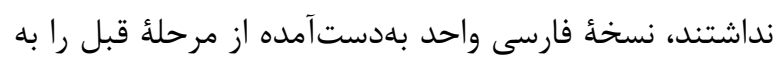

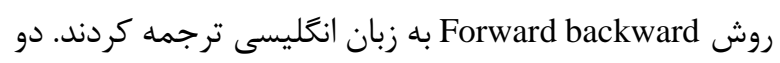

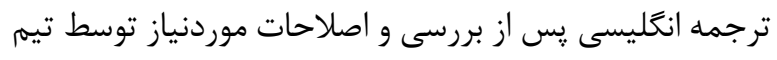

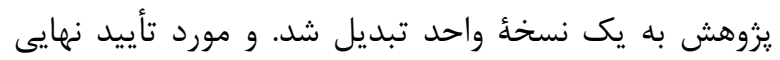
طراح اصلى اين يرسشنامه قرار كرفت.

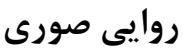

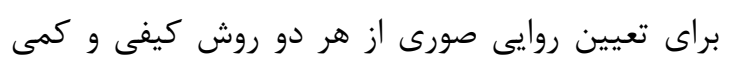

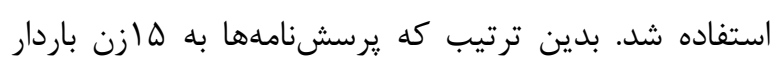

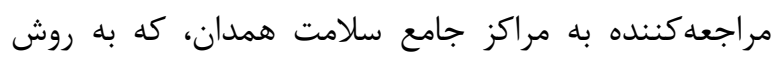

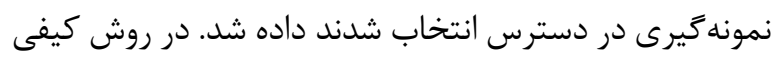

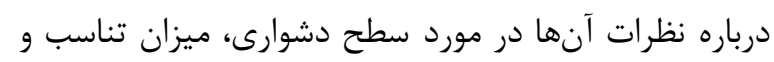

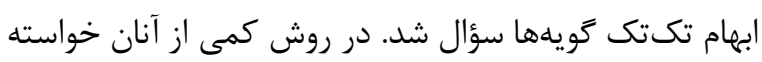

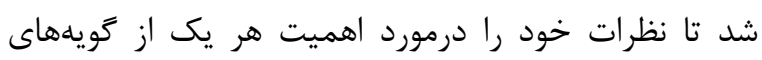

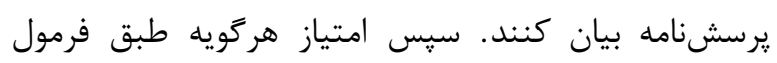
مربوطه (نمره تأثير آيتم= فراوانى (درصد) × اهميت) محاسبه

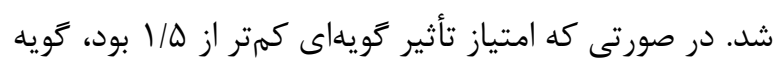

حذف مىشد [1/1].

\section{رواييى محتوا}

روايى محتوا به دو روش محنوا كيفى و كمى انجام شد.

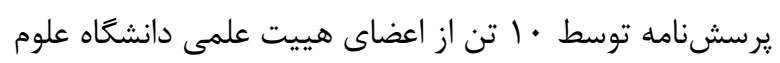
يزشكى همدان بررسى و يس از انجام اصلاحات تأييد كرديد.

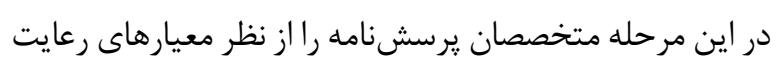

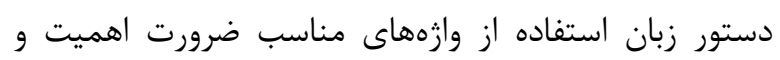

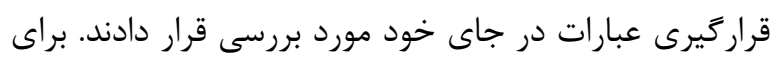

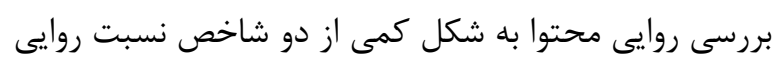
محتوا (CVR) و شاخص روايى محتو به محتوا (CVI) استفاده شد.

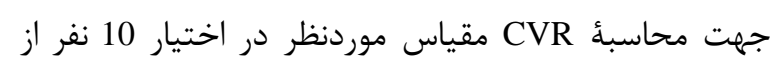

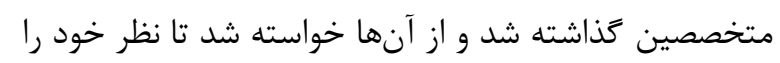

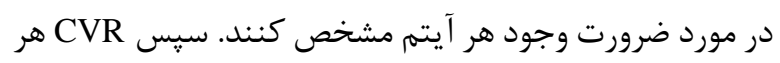

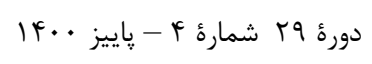

$$
\text { مجله مراقبت يرستارى و مامايى ابنسينا }
$$


ييرسون براى بررسى ارتباط بين يرسشنامه خودكارآمدى

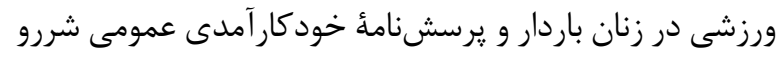

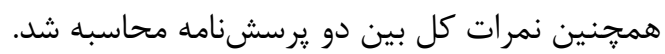

\section{بافته ها}

نتايج مربوط به هر بخش از مطالعه در زير توضيح داده

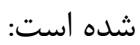

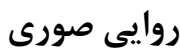

طى بررسى روايى صورى به روش كيفى يافتهها نشان داد

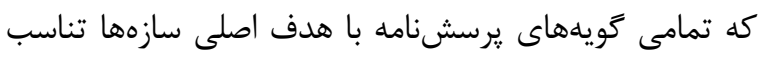

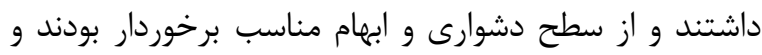

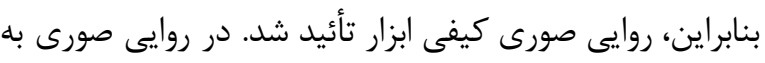

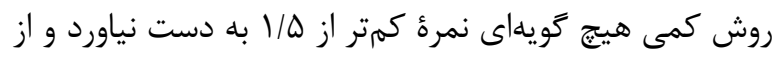

$$
\text { يرسشنامه حذف نشد. }
$$

\section{روايى محتوا}

جهت انجام روايى محتواى كيفى نظرات متخصصين طبق

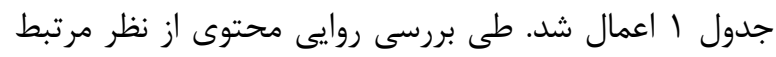

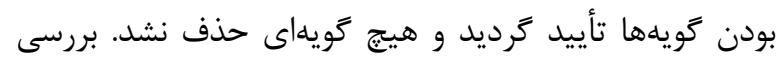

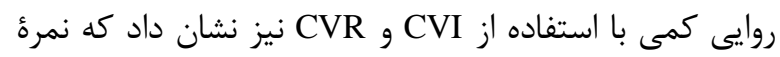

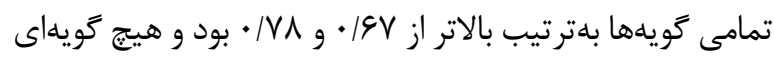

$$
\text { در اين مرحله حذف نشد (جدول ؟ r). }
$$

اساس ارزش ويزٔه بزركتر از ا و نمودار شنريزه صورت گرفت. در روش نمودار شن ريزه، تعداد عاملها با استفاده از شيب إنب دردي

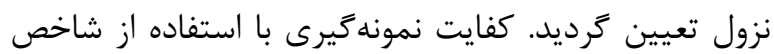

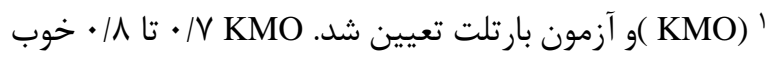

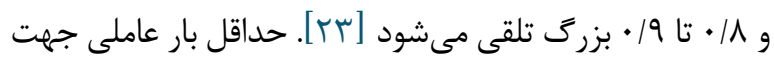
استخراج عاملها، هَّ/ • در نظر كرفته شد. هايايى يايايى ابزار با استفاده از سنجش ثبات درونى و آزمون - باز آزمون

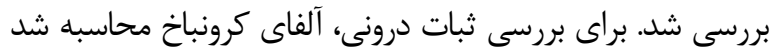

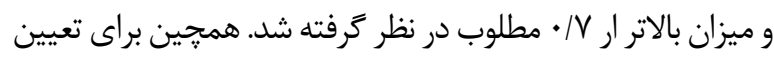

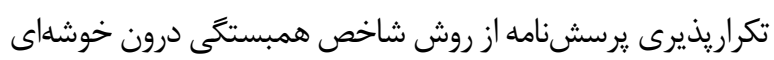

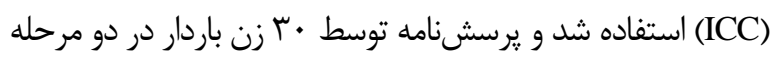

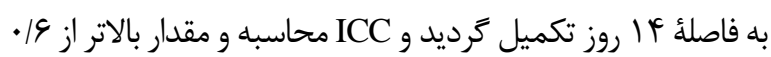

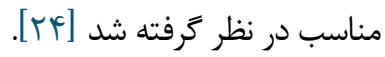

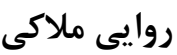

در مطالعُ حاضر يرسشنامه خودكارآمدى عمومى شرر

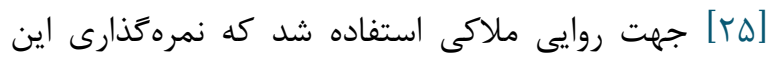

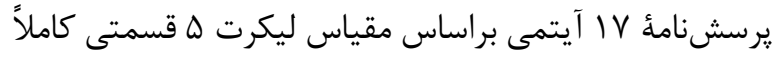

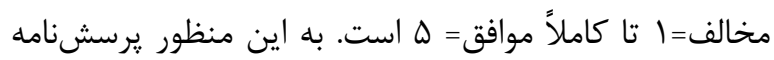
خودكار آمدى ورزشى و يرسشنامه خودكارآمدى عمومى شرر

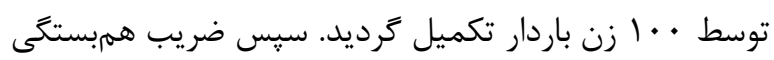

\section{تويه يس از انجام اصلاحات \\ من مى توانم راه و روش فعاليت كردن و ورزش كردن را ييدا كنه. من مى توانم راه هاى مقابله با موانع ورزش كردن يا فعاليت بدنى را يبيدا كنم بعد از مدتى كه ورزش كردن رامتوقف كردم براى دوباره ورزش كردن به خودم انكيزه مى دهم}

جدول ا. نتايج روايى محتواى كيفى

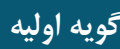

من مى توانم راه و روش فعال بودن از لحاظ فيزيكى و ورزش كردن را

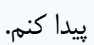
من مى توانم در برخورد با هر مانعى براى فعاليت بدنى يا ورزش كردن

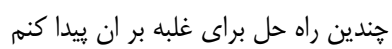

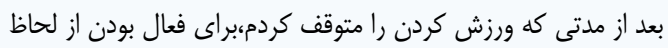

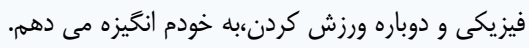

\begin{tabular}{|c|c|c|}
\hline 1 & 1 & من مى توانم اكر سخت تلاش كنم، بر موانع و مشكلات در رابطه با فعاليت بدنى و ورزش كردن غلبه كنم \\
\hline 1 & $\cdot / \Lambda$ & من مىتوانم راه و روش فعاليت كردن و ورزش كردن را ييدا كنم. \\
\hline 1 & 1 & من مى توانم به اهداف ورزشى و فعاليت بدنى موردنظرم برسم. \\
\hline 1 & $\cdot / \wedge$ & من مىتوانم راههاى مقابله با موانع ورزش كردن يا فعاليت بدنى را ييدا كنه \\
\hline 1 & $\cdot / \wedge$ & من مى توانم از لحاظ فيزيكى فعال باشم يا ورزش كنم حتى وقتى خسته هستم \\
\hline 1 & 1 & من مى توانم از لحاظ فيزيكى فعال باشم يا ورزش كنم حنى وقتى احساس مى كنم افسرده هستم \\
\hline 1 & 1 & من مى توانم از لحاظ فيزيكى فعال باشم يا ورزش كنم حتى بدون حمايت خانواده و دوستانم \\
\hline
\end{tabular}

جدولr. نمرات تاثير آيتم و CVR و CVI

\section{CVR كويه ها}

${ }^{1}$ Kaiser-Meyer-Olkin

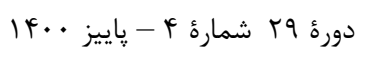

مجله مراقبت يرستارى و مامايى ابنسينا 


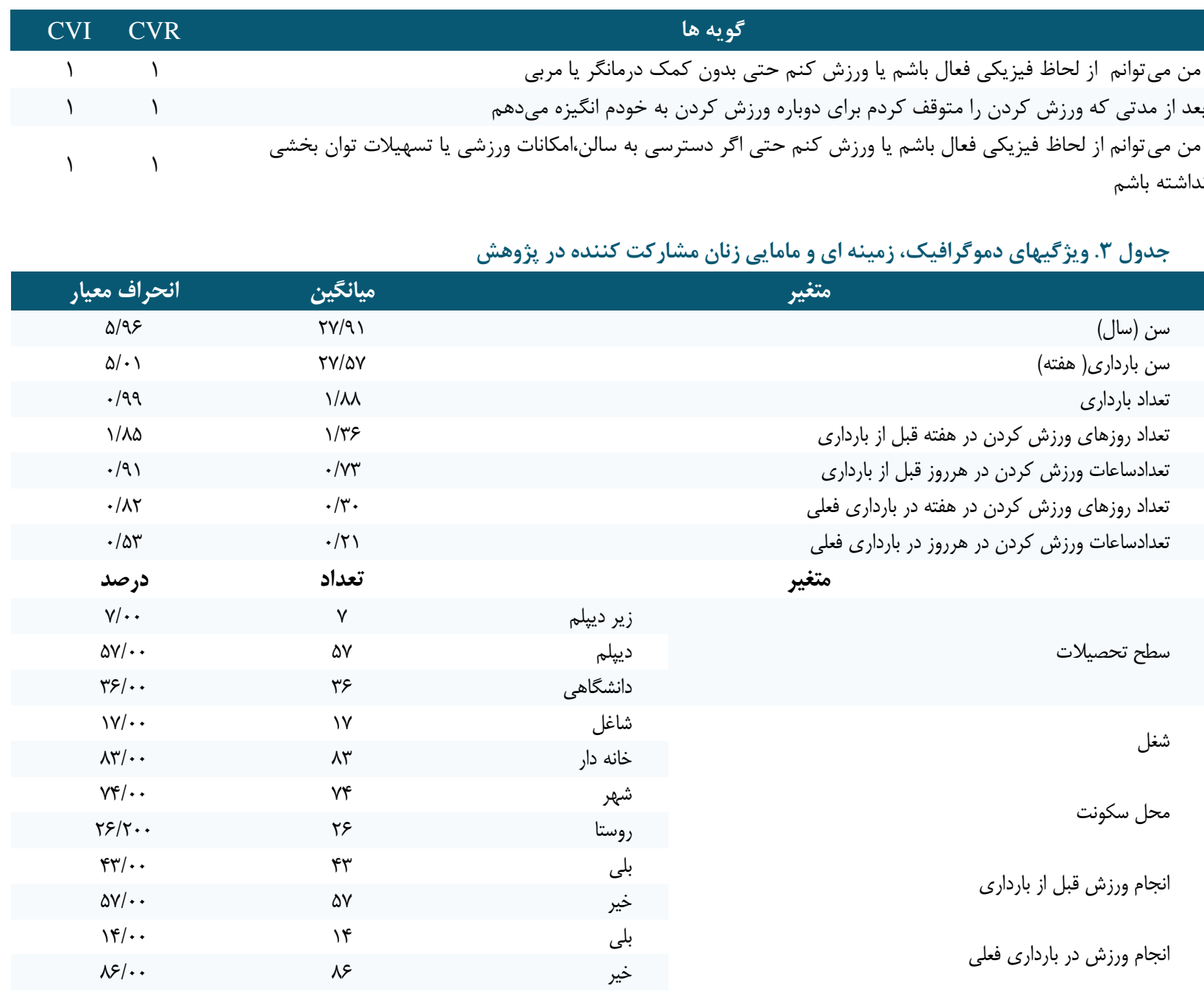

بامنظور تعيين روايى سازه يرسشنامه، تحليل عاملى

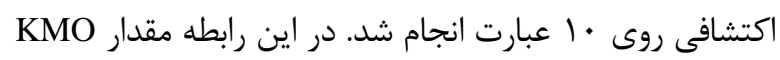

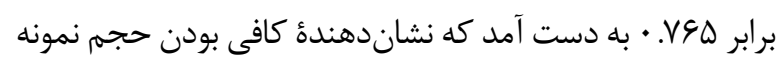
بود. همجنين نتيجهُ تست كرويت بارتلت برابر معنى دار بود كه

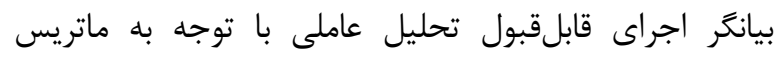
همبستخى در نمونهُ مورد مطالعه بود (جدول أ). جدول f. نتايج آزمون KMO و تست كرويت بارتلت

\begin{tabular}{|c|c|c|}
\hline -/VEa & \multicolumn{2}{|c|}{ معيار كيسر-ماير-الكين براى بررسى كفايت نمونه } \\
\hline$r 94 / 990$ & مقدار تقريبى كاى دو & \\
\hline is & 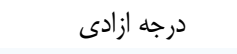 & كرويت بارتلت \\
\hline$<\cdot / \cdots+1$ & p-value & \\
\hline
\end{tabular}

روايى سازه جهت تعيين روايى سازه · ا نفر از زنان باردار وارد مطالعه

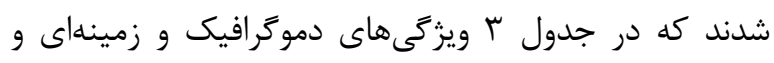
مامايى مربوط به آنها نشان داده شده است. ميانخين سن شركت كنند

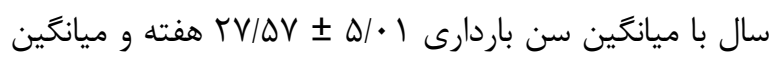

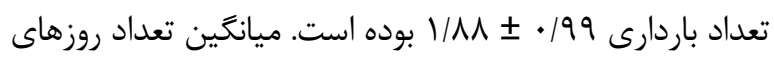

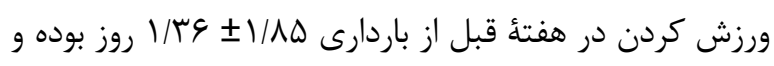

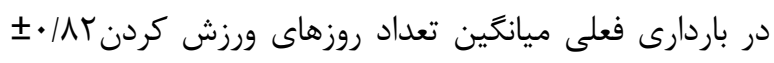

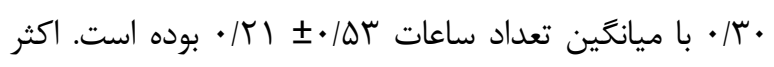

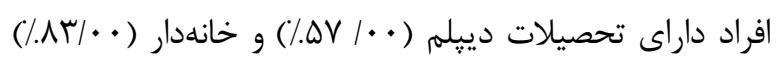

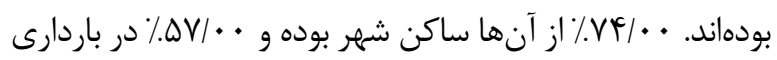
فعلى ورزش نمى كردند. 
جدول ه. واريانس عاملهاى ابزار مورد بررسى در تحليل عاملى اكتشافى

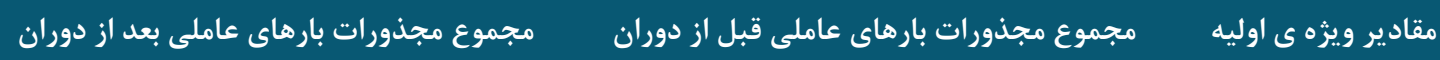

\begin{tabular}{|c|c|c|c|c|c|c|c|c|}
\hline تجمعى & واريانس & كل & تجمعى درص & واريانس & كل & تجمعى & وراريانس & 5 \\
\hline 27.329 & 27.329 & 2.733 & 37.524 & 37.524 & 3.752 & 37.524 & 37.524 & 3.752 \\
\hline 1.544 & 24.215 & 2.421 & 51.544 & 14.020 & 1.402 & 51.544 & 14.020 & 1.402 \\
\hline
\end{tabular}

ابزار محاسبه شد كه مقدار آن در هر دو حيطه و كل مقياس

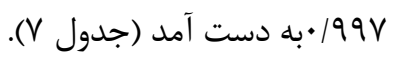

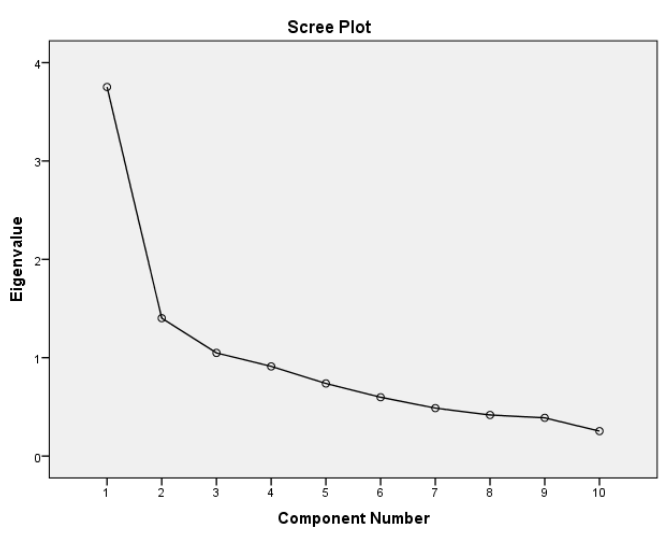

نمودار 1. نمودار شنريزه عاملهاى ابزار

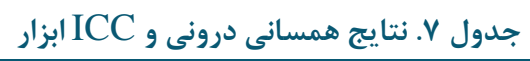

\begin{tabular}{|c|c|c|}
\hline $\mathrm{ICC}$ & ضر يب الفاى كرونباخ & سازه \\
\hline.$/ 99$ & $\cdot / V Q$ & حيطه اول (fايتهم) \\
\hline .199 & •/Vq & حيطه دوم ( (ايتم) \\
\hline.$/ 99$ & • $|A|$ & كل ابزار \\
\hline
\end{tabular}

روايى ملاكى

جهت تعيين اعتبار ملاكى يرسش ملامه خودكارآ آمدى عمومى

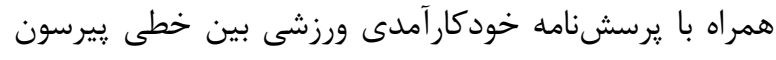

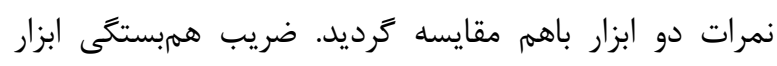

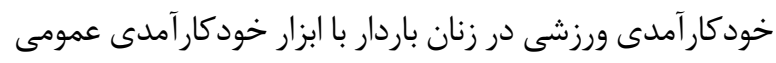

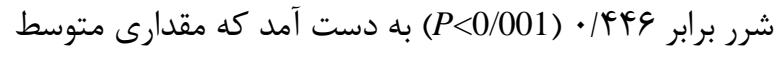

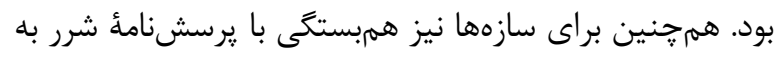

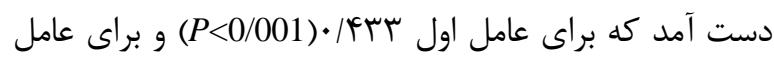

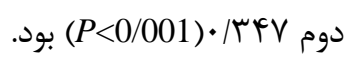

\section{بحث}

با توجه به اهميت مراقبت از زنان باردار و ضرورت فراهم

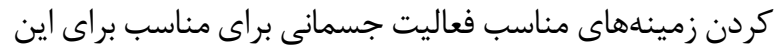
افراد نياز به يك ابزار مناسب جهت اندازهكيرى ميزان باورهاى برى
نتايج تحليل عاملى اكتشافى نشان داد ه.r.r\% از واريانس

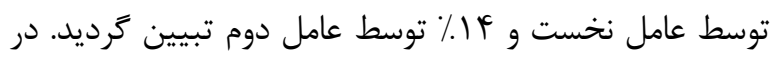

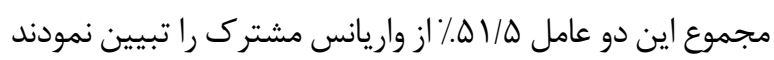

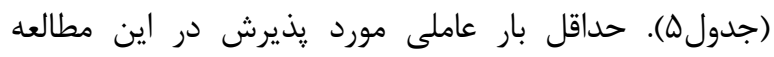

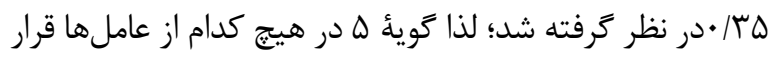

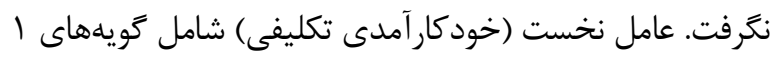

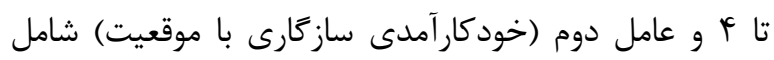
كويههاى 9 تا•ابود (جدول (

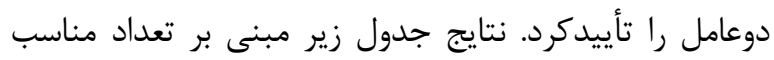

\begin{tabular}{|c|c|c|}
\hline \multirow{2}{*}{ كويه ها } & \multicolumn{2}{|c|}{ عاملها } \\
\hline & 1 & 2 \\
\hline QI & & - /VGD \\
\hline Qr & & $\cdot|A| V$ \\
\hline Qr & & - MYT \\
\hline$Q^{F}$ & $\cdot / r V F$ & $\cdot 19 \cdot V$ \\
\hline QD & & \\
\hline $\mathrm{Q}^{4}$ & . & \\
\hline QV & - $/ V F \Delta$ & \\
\hline QA & $\cdot / V \mid S$ & \\
\hline Q9 & $\cdot \mid \Delta \Delta T$ & $\cdot /{ }^{\prime} \wedge$. \\
\hline Ql• & - /VVq & \\
\hline
\end{tabular}
عامل ها را بلهصورت تصويرى نشان مى دهد (نمودار (1).

جدول צ. بار عاملى عوامل استخراج شده از تحليل عاملى با

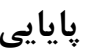

براى محاسبة همسانى درونى ضريب آلفاى كرونباخ استفاده شد كه نتايج ذكرشده در جدول V نشاندهنده همسانى درونى

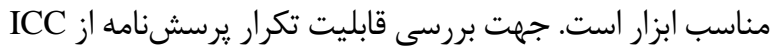

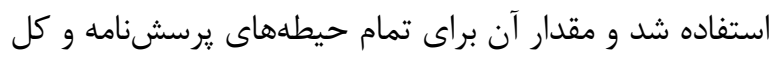

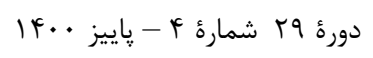

$$
\text { مجله مراقبت يُرستارى و مامايى ابنسينا }
$$


در اين مطالعه، קايايى كل يرسشنامه با استفاده از روش

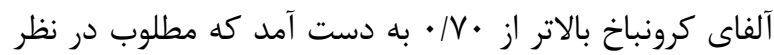

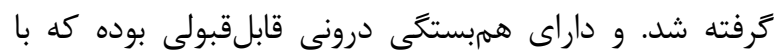

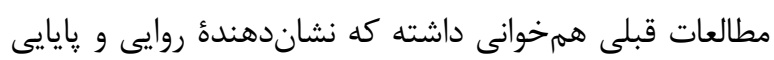

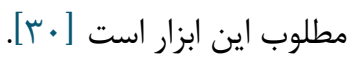

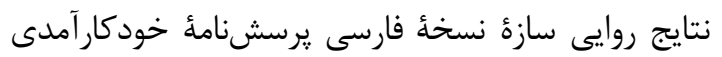

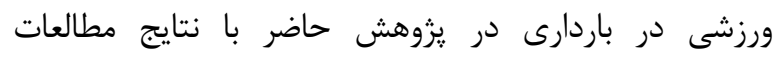

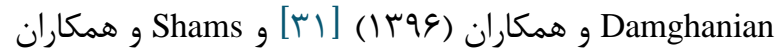

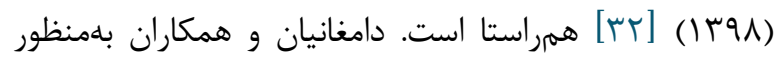

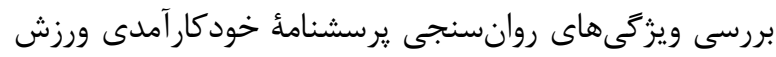

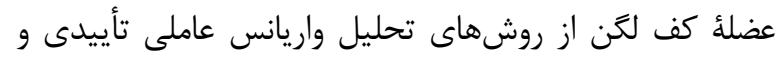

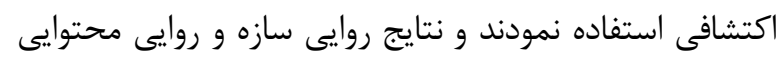

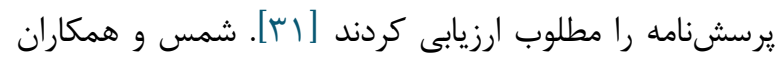

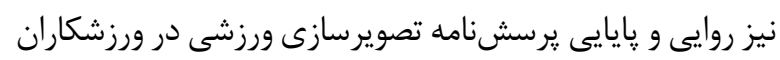

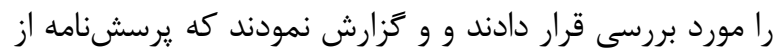

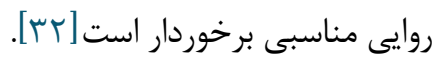

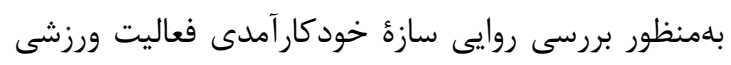
در زنان باردار جامعه ايران، از تحليل عاملى تأييدى با روش

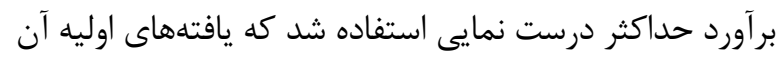

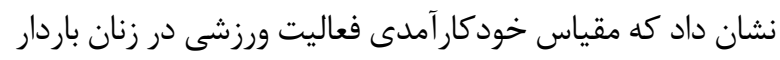

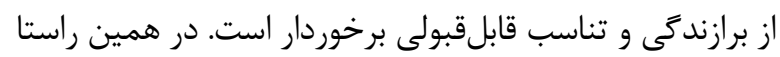
از نقاط قوت مطالعه حاضر مىتوان به تعداد مناسب نمونه با

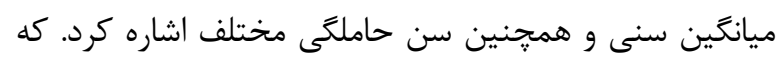

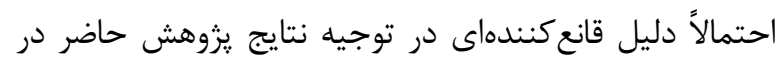

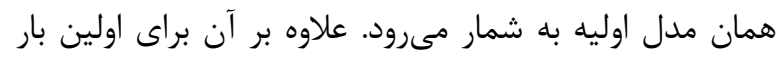

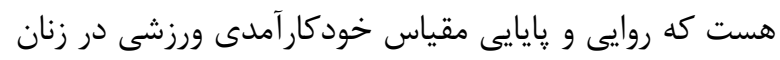

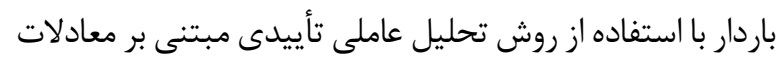

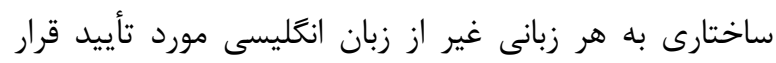

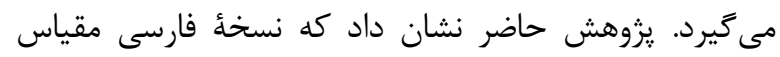

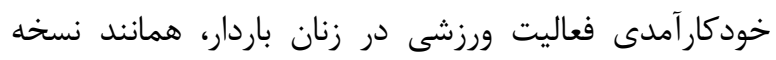

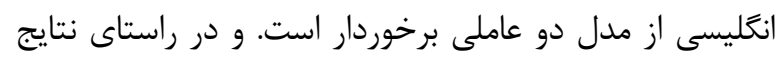

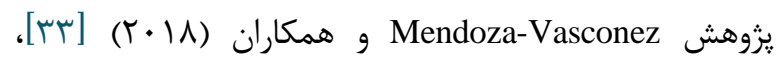

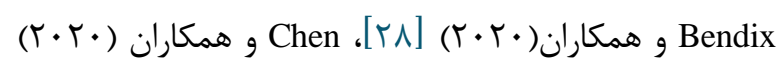

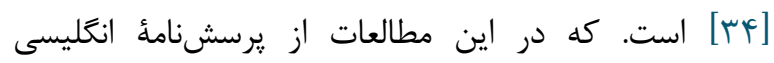
خودكارآمدى ورزشى در كشورهاى آمريكا، دانمارك استفاده آنسا

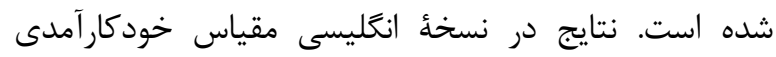

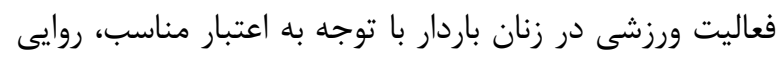

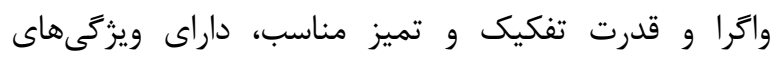

خودكارآمدى براى شركت در فعاليتهاى ورزشى زنان باردار

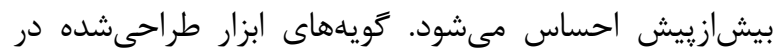

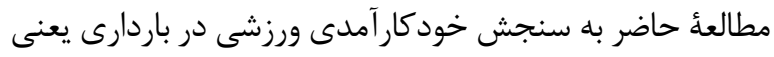
قضاوت و تفكر زن باردار در مورد توانايىهايش براى انجام ورزش باري

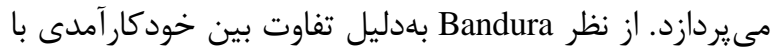

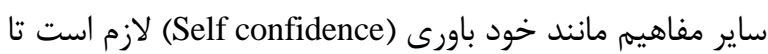

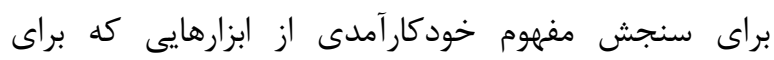

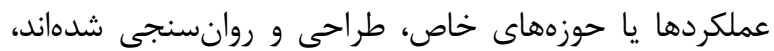

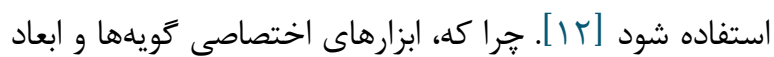

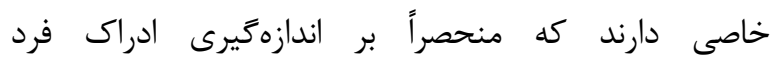
ازتوانمندىهايش در همان حوزه اختصاصى تأكيد مى كنيند

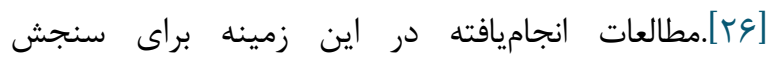

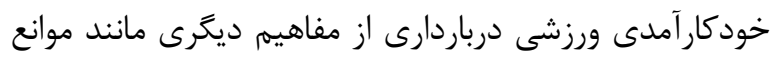

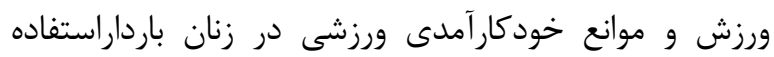

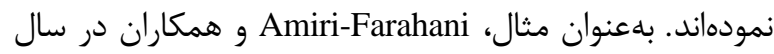

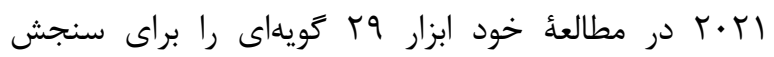

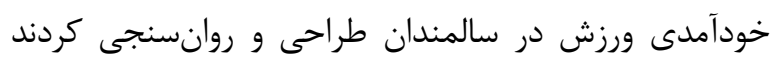

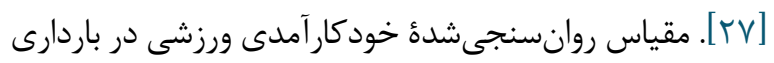

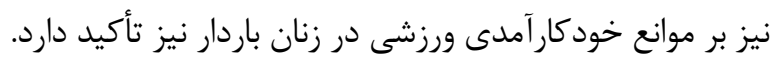

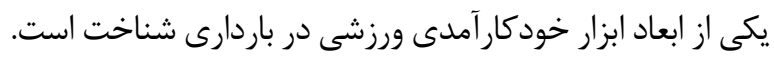

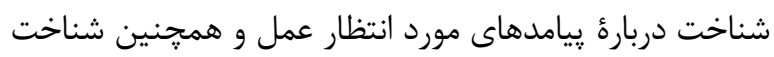
دربارة اهميت رفتار يكى از مهمترين عوامل مؤثر در تلاش زنان هان

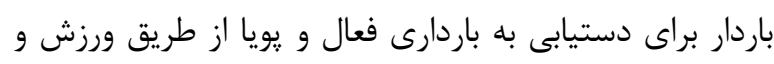

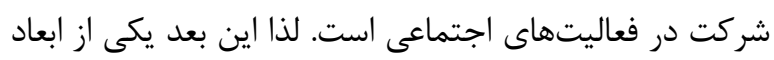

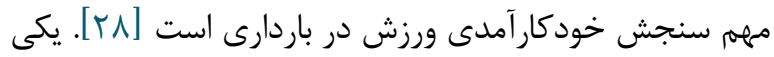
ديكر از ابعاد ابزار طراحىشده در مطالعهُ حاضر سازكارى باريا

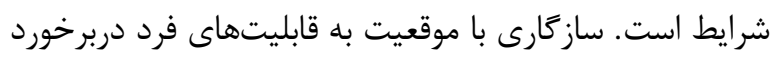

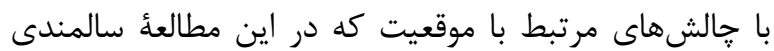

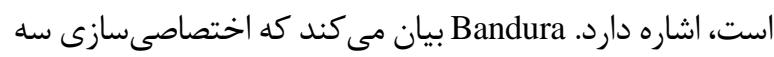

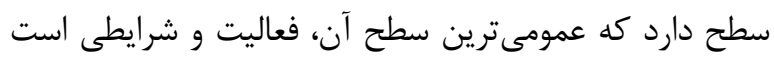

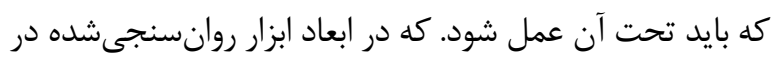

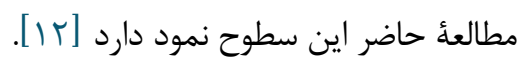

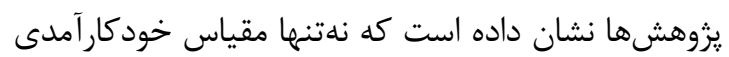

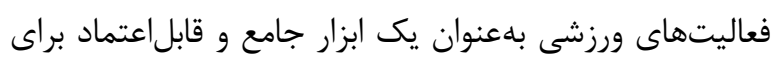

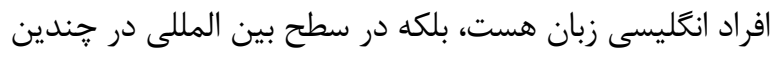

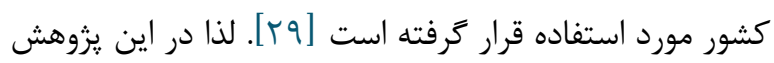

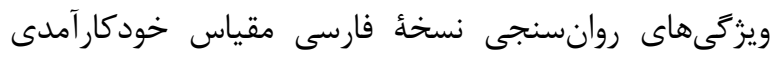
ورزشى در زنان باردار بررسى شده است.

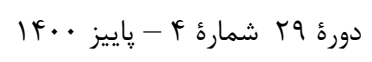

$$
\text { مجله مراقبت يرستارى و مامايى ابنسينا }
$$


عاملى تأييدى، ضريب آلفاى كرونباخ همبستكى درون طبقهاى

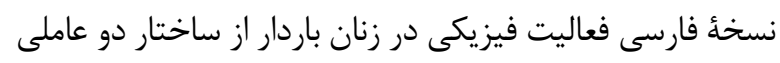

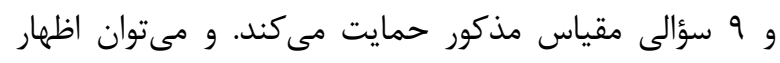

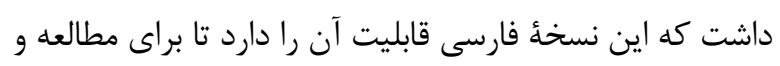

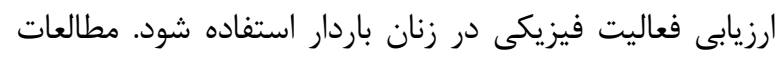

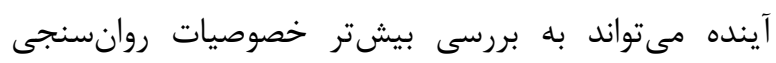

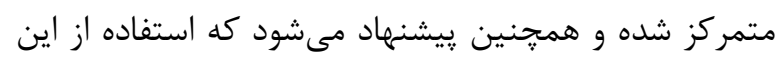

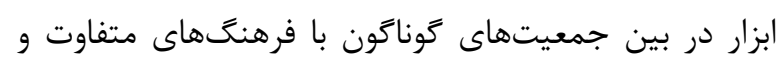

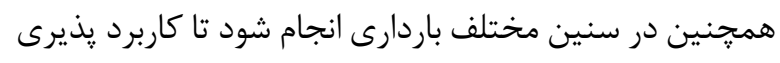

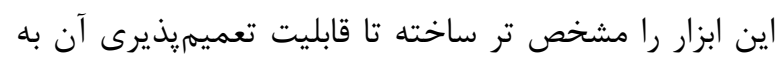

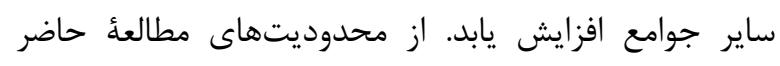

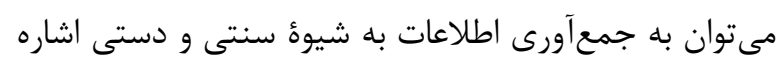

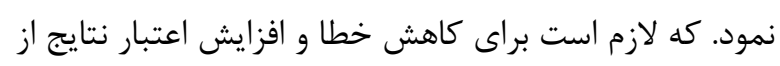

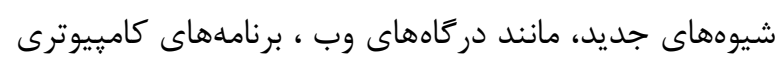

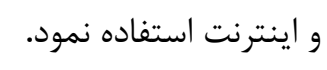

$$
\text { نتيجه گيرى }
$$

تحليل دادههاى مطالعه نشان داد كه از ابزار روانسنجى

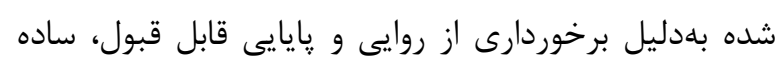

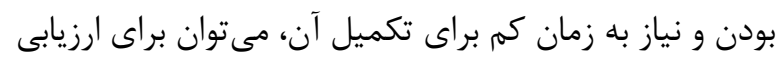
خودكارآمدى ورزش در دوران باردارى استفاده نمود.

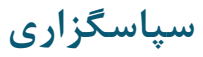

اين مقاله، حاصل انجام پايان نامٔ كارشناسىارشد مشاوره

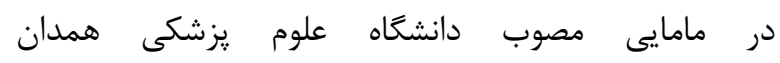
(91.GYGKVTr)

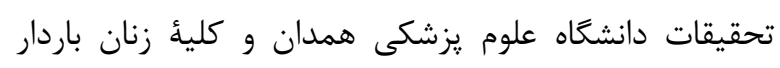

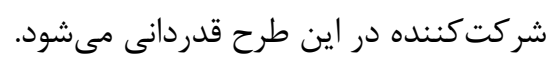

$$
\text { تعارض در منافع }
$$

بين نويسندكان هيجَّونه تعارضى در منافع وجود ندارد.

$$
\text { منابع مالى }
$$

روانسنجى رضايت بخشى بود. با توجه به نزديكى بسيار زياد

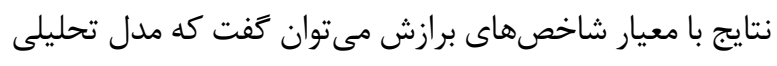

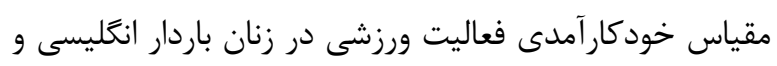

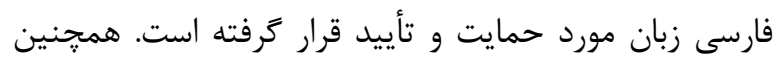

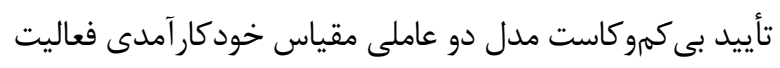

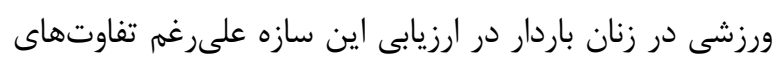

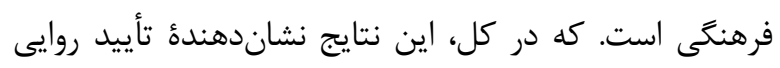

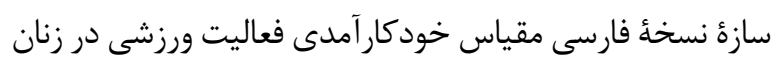

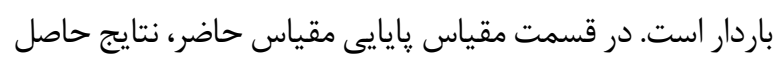

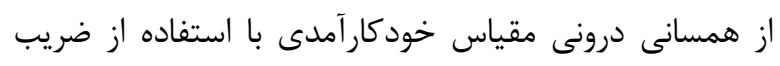

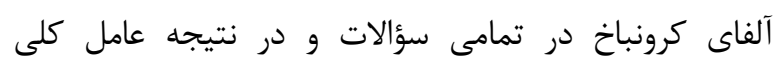

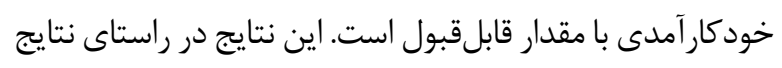

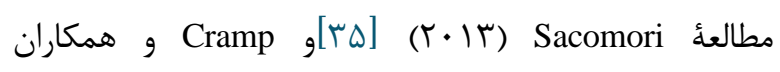

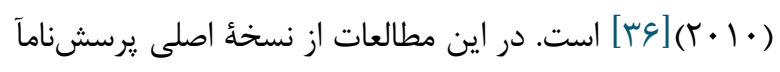

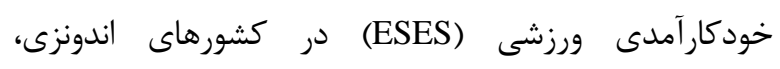

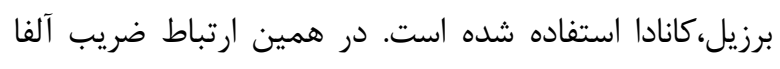

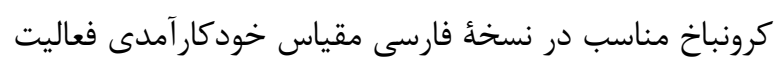

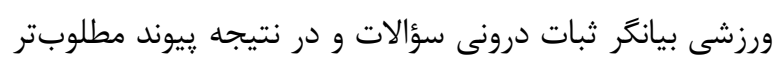

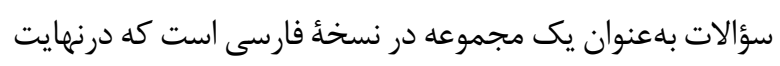

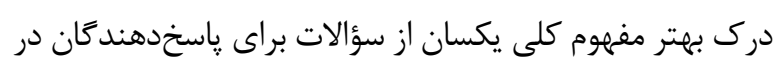

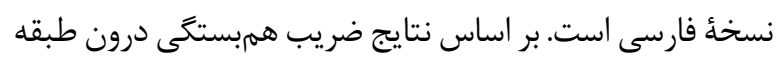

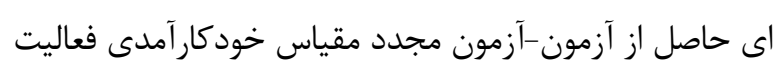

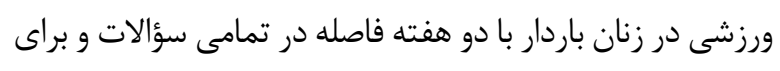

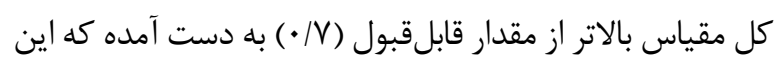

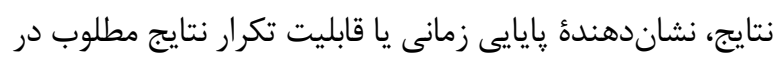

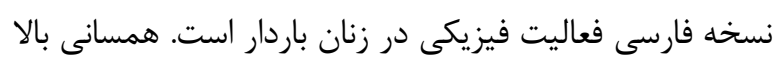

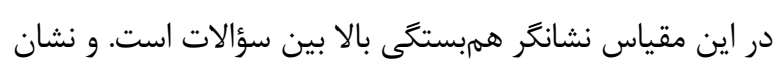

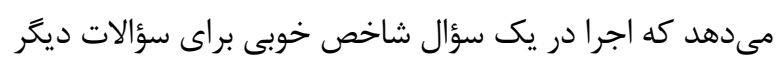

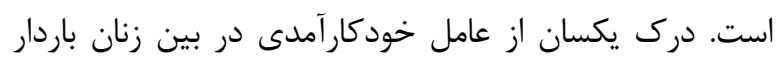

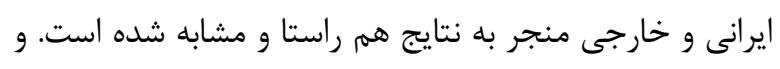

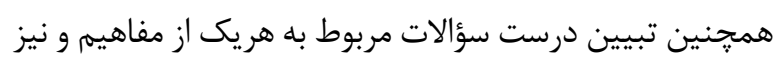

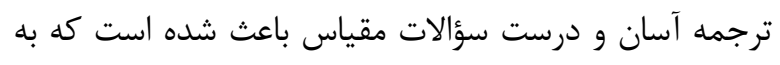

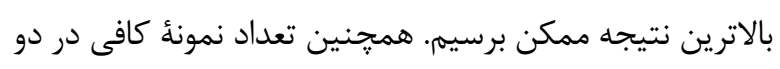

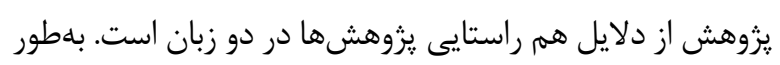

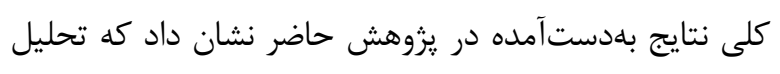




\section{References}

1. Walasik I, Kwiatkowska K, Kosińska Kaczyńska K, Szymusik I. Physical activity patterns among 9000 pregnant women in poland: A cross-sectional study. Int J Environ Res public health. 2020;17(5):1771. [DOI:10.3390/ijerph17051771] [PMID] [PMCID]

2. Nascimento SL, Surita FG, Godoy AC, Kasawara KT, Morais SS. Physical activity patterns and factors related to exercise during pregnancy: a cross sectional study. PLoS One. 2015;10(6): e0128953. [PMCID] [DOI:10.1371/journal.pone.0128953] [PMID]

3. da Silva SG, Hallal PC, Domingues MR, Bertoldi AD, da Silveira MF, Bassani D et al., A randomized controlled trial of exercise during pregnancy on maternal and neonatal outcomes: results from the PAMELA study. Int J Behav Nutr Phys Act. 2017. 14(1):1-11. [DOI:10.1186/s12966-017-0632-6] [PMID] [PMCID]

4. Beetham KS, Giles C, Noetel M, Clifton V, Jones JC, Naughton $\mathrm{G}$. The effects of vigorous intensity exercise in the third trimester of pregnancy: a systematic review and meta-analysis. BMC Pregnancy and Childbirth. 2019. 19(1):1-18. [DOI:10.1186/s12884-019-2441-1] [PMID] [PMCID]

5. Hinman SK, Smith KB, Quillen DM, Smith MS. Exercise in pregnancy: a clinical review. Sports Health, 2015. 7(6):527-31. [DOI:10.1177/1941738115599358] [PMID] [PMCID]

6. Petrov Fieril K, Glantz A, Fagevik Olsen M. The efficacy of moderate-to-vigorous resistance exercise during pregnancy: a randomized controlled trial. Acta Obstet Gynecol Scand. 2015;94(1):35-42. [DOI:10.1111/aogs.12525] [PMID]

7. Barakat R, Perales M, Garatachea N, Ruiz JR, Lucia A. Exercise during pregnancy. A narrative review asking: what do we know? Br J Sports Med. 2015;49(21):137781. [DOI:10.1136/bjsports-2015-094756] [PMID]

8. Schultz DP, Schultz SE. Theories of personality. 2016: Cengage Learning.

9. DeGeest, D. and K.G. Brown. The role of goal orientation in leadership development. Hum Resour Dev Q. 2011:(2):157-75. [DOI:10.1002/hrdq.20072]

10. Sivrikaya MH. The role of self-efficacy on performance of sports skills of football players. J Educ Train Studies. 2019;6(n12a):75-9. [DOI:10.11114/jets.v6i12a.3952]

11. Peterson MS, Lawman HG, Wilson DK, Fairchild A, Van Horn ML.The association of self-efficacy and parent social support on physical activity in male and female adolescents. Health Psychol. 2013;32(6):666. [DOI:10.1037/a0029129] [PMID] [PMCID]

12. Bandura, A., Guide for constructing self-efficacy scales, in Self-Efficacy Beliefs of Adolescents. 2005. Information Age Publishing.

13. Sebyani M. Psychometric Properties of Persian Version of Re-Injury Anxiety Inventory (RIAI) in Injured Athletes. Sport Psychol Studies. 2019;8(27): $157-72$.
14. Schmitter M, Spijker J, Smit F, Tendolkar I, Derksen AM, Oostelbos P et al., Exercise enhances: study protocol of a randomized controlled trial on aerobic exercise as depression treatment augmentation. BMC Psychiatry. 2020;20(1):1-1. [DOI:10.1186/s12888020-02989-z] [PMID] [PMCID]

15. Evenson KR. Towards an understanding of change in physical activity from pregnancy through postpartum. Psychol Sport Exerc. 2011;12(1):36-45. [PMID] [PMCID] [DOI:10.1016/j.psychsport.2010.04.010]

16. Cooney GM, Dwan K, Greig CA, Lawlor DA, Rimer J, Waugh FR et al., Exercise for depression Cochrane Database. Syst Rev. 2013(9): CD004366. [DOI:10.1002/14651858.CD004366.pub6] [PMID]

17. Bland HW, Melton BF, Marshall ES, Nagle JA. Measuring exercise self-efficacy in pregnant women: psychometric properties of the pregnancy-exercise self-efficacy scale (P-ESES). J Nurs Meas. 2013;21(3):349-59. 3749.21.3.349] [PMID]

18. Hajizadeh E, Asghari M. Asghari, Statistical methods and analyses in health and biosciences a research methodological approach. Tehran: Jahade Daneshgahi Publications. 2011;395.

19. Lawshe $\mathrm{CH}$. A quantitative approach to content validity 1. Pers Psychol. 1975;28(4):563-75. [DOI:10.1111/j.1744-6570.1975.tb01393.x]

20. Hungler BP, Beck CT, Polit DF. Essentials of nursing research: methods, appraisal, and utilization. 1997: Lippincott-Raven.

21. Plichta SB, Kelvin EA. Munro's Statistical Methods for Health Care Research. 2012: Wolters Kluwer Health/Lippincott Williams \& Wilkins.

22. Williams B, Onsman A, Brown T.Onsman, and T Brown, Exploratory factor analysis: A five-step guide for novices. Australas J Paramedicine. 2010;8(3). https://doi.org/10.33151/ajp.8.3.93 [DOI:10.33151/ajp.8.3.93.]

23. Nia HS, Ebadi A, Lehto RH, Mousavi B, Peyrovi H, Chan YH. Reliability and validity of the persian version of templer death anxiety scale-extended in veterans of Iran-Iraq warfare. Iran $\mathbf{J}$ Psychiatry Behav Sci. 2014;8(4):29.

24. Shoukri MM. Measures of interobserver agreement and reliability. 2010: CRC press. [DOI:10.1201/b10433]

25. Sherer M, Maddux JE, Mercandante B, Prentice-Dunn S, Jacobs B, Rogers RW.The self-efficacy scale: Construction and validation. Psychol reports. 1982;51(2):663-71. [DOI:10.2466/pr0.1982.51.2.663]

26. Mulyadi S, Basuki AH, Rahardjo W. Rahardjo, Student's tutorial system perception, academic selfefficacy, and creativity effects on self-regulated learning. Procedia-Soc Behav Sci. 2016;217:598-602. [DOI:10.1016/i.sbspro.2016.02.059]

27. Amiri-Farahani L, Ahmadi K, Hasanpoor-Azghady SB, Pezaro S. Development and psychometric testing

$$
\text { دورة جr شماره }
$$$$
\text { مجله مراقبت يرستارى و مامايى ابنسينا }
$$ 
of the 'barriers to physical activity during pregnancy scale' (BPAPS). BMC Public Health. 2021;21(1):1-9. [DOI:10.1186/s12889-021-11511-3] [PMID] [PMCID]

28. Bendix EJ, Krøner FH, de Place Knudsen S, Bendix JM, Molsted S. Cross-Cultural adaption, translation and reliability tests of the Danish version of the pregnancy exercise self-efficacy scale. Sex Reprod Healthc. 2020;26:100542.

[DOI:10.1016/j.srhc.2020.100542] [PMID]

29. Chan CW, Au Yeung E, Law BM. Effectiveness of physical activity interventions on pregnancy-related outcomes among pregnant women: a systematic review. Int J Environ Res Public Health. 2019;16 (10):1840. [DOI:10.3390/ijerph16101840] [PMID] [PMCID]

30. Boonyoung N, Chunuan S. Evaluation of the Psychometric Properties of Self-Efficacy in Performing Maternal Role for First Time Pregnant Adolescents in Indonesia. Songklanagarind J Nurs. 2020;40(2):10-23.

31. Damghanian M, Pakgohar M, Tavousi M, Dehghan Nayeri N, Najafi M, Kharaghani R et al., Psychometric analysis of the Broome pelvic floor muscle exercise self-efficacy scale in women with urinary incontinence. Hayat J. 2018;23(4):307-17.
32. Shams A, Shamsipour Dehkordi P.Psychometric Properties of Sport Imagery Questionnaire among Iranian National Team's Athletes. Sport Sci Res Institute of Iran. 2017;9 (28): 17-36.

33. Mendoza-Vasconez AS, Marquez B, Benitez TJ, Marcus BH. Psychometrics of the self-efficacy for physical activity scale among a Latina women sample. BMC Public Health. 2018;18(1):1-0.1097 https://doi.org/10.1186/s12889-018-5998-0 [DOI:10.1186/s12889-018-5998-0.] [PMID] [PMCID]

34. Chen FT, Etnier JL, Chan KH, Chiu PK, Hung TM, Chang YK. Effects of exercise training interventions on executive function in older adults: a systematic review and meta-analysis. Sports Med. 2020;50:1451-67. [DOI:10.1007/s40279-020-01292-x] [PMID] [PMCID]

35. Sacomori C, Cardoso FL, Porto IP, Negri NB. The development and psychometric evaluation of a selfefficacy scale for practicing pelvic floor exercises. Braz J Phy Ther. 2013;17:336-42. [DOI:10.1590/S141335552013005000104] [PMID]

36. Cramp AG, Bray SR. Understanding exercise selfefficacy and barriers to leisure-time physical activity among postnatal women. Matern Child Health J. 2011;15(5):642-51 [DOI:10.1007/s10995-010-0617-4] [PMID] 